\title{
Political ideology and attitudes toward vaccination: A study report
}

Working paper, 06/27/2020

Gabriela Czarnek, Małgorzata Kossowska, \& Paulina Szwed

Jagiellonian University

This research was supported by RIKSBANKENS JUBILEUMSFOND (\#M18-0310:1; 2019-2024)

This paper has not been peer-reviewed. For more information, please contact us at gabriela.czarnek@uj.edu.pl 


\begin{abstract}
As the relationship between ideology and attitudes towards vaccinations is usually analysed using data collected in the US context, in this report we focus on the vaccination attitudes in Europe, with a special focus on Poland. The current findings show that the effects of ideology on vaccine attitudes are insignificant when European context is considered. Instead, we found that ideology interact with political interest: among people interested in politics, right-wing ideology had negative effect on vaccine attitudes and beliefs, whereas for people not interested in politics, the effects of ideology were insignificant. However, the interaction effects were rather modest and did not provide support for the hypothesis that there is a "liberal bias" against vaccination. We suggest that it insignificant effects of ideology on vaccine attitudes in the European context is related to the fact that vaccines have not become a strongly politicized issue as it is in the US.
\end{abstract}

Keywords: vaccines, vaccination, political ideology, education, political interest, Europe, Eurobaromater 
Although vaccination is a domain with strong scientific and medical consensus, public's attitudes are influenced by ideology. The results are however mixed and inconclusive. For example, the claims of disproportionately liberal bias against vaccinations that have been widely repeated, have so far little empirical support (Baumgaertner et al., 2018). Kahan (2014) detects no significant political or religious differences in vaccine risk perceptions. Lewandowsky et al. (2013) find that opposition to vaccines is predicted most strongly by tendency to believe in conspiracies, secondarily by a free-market ideology, and most weakly by liberalism. Rutjens and others (2015) suggested that it is religiosity, alongside moral purity concerns, and not conservatism best predicts vaccination skepticism. Finally, Hornsey and others (2018) demonstrated that anti-vaccination attitudes were highest among those who were high in conspiratorial thinking, high in reactance, reported high levels of disgust toward blood and needles, and had strong individualistic/hierarchical worldviews.

As the relationship between ideology and attitudes towards vaccinations is usually analysed on data coming from the US context, in our analysis we analysed European data with special focus on Poland. Contrary to the US data analysis, we do not expect the link between ideology and attitudes towards vaccines as vaccines has not become a strongly politicized issue as in the US.

\section{Method}

\section{Participants}

To analyse the effects of political ideology on vaccination beliefs and attitudes, we used data from Eurobarometer 91.2 (European Commission, 2019). Eurobarometer is a public opinion poll ran on behalf of the European Commission and covers all the European Union member states. We focused on the Eurobarometer 91.2 as it contains the most up-to-date data on the citizens' beliefs and attitudes toward vaccination. 
Eurobarometer 91.2 contains 27,524 cases. After removing cases with missing data on demographic variables and political ideology, there were 21,699 cases available $(10,234$ men, 11,465 women; $\left.\mathrm{M}_{\mathrm{age}}=52.35, \mathrm{SD}_{\mathrm{age}}=17.81\right)$. Apart from analysing full data set, we ran separate analysis only for Poland ( $N=738,283$ men, 455 women; average age was $M=51.32, S D=16.04$, average age when completed formal education $M=19.41, S D=3.60)$.

\section{Measures}

Education was measured as the age in which one stopped full-time education ("How old were you when you stopped full-time education?", $M=19.52 ; S D=4.71$ ). Because of this specific format of measuring level of education, we decided to remove responses from participants who reported being 40 years old or more. Gender was recoded into 0 ("man") and 1 ("woman"). Political ideology was measured with left-right identification ("In political matters people talk of "the left" and "the right". How would you place your views on this scale?"; 1 = "left", $10=$ "right"; $M=4.30, S D=2.20$ ).

Political interest was analysed using responses to a series of questions "When you get together with friends or relatives, would you say you discuss frequently, occasionally or never about...?": (1) "National political matters"; (2) "European political matters"; (3) "Local political matters" (1 = "frequently", 2 = "occasionally", 3 = "never", 4 = "don't know"; we used scores provided by Eurobarometer "polintr" which was the summarized responses for the three questions). We reversescored these responses $(M=1.65, S D=0.96)$, so that the higher the scores, the higher political interest.

With regard to vaccination, there were 4 questions about the beliefs and 5 questions capturing the attitudes. The questions measuring beliefs about vaccines were the following: (1) "Vaccines overload and weaken the immune system" (false); "Vaccines can cause the disease against which they protect" (false); (3) "Vaccines can often produce serious side-effects" (false); "Vaccines are rigorously tested before being authorised for use" (correct). Participants could respond that a given statement is true, false, or that they do not know the answer. We recoded these responses into wrong $=0$, don't 
know $=0.5$, correct $=1$ and averaged them $(M=0.48, S D=0.20)$; thus, the higher the value, the more positive vaccine-related beliefs.

The attitudes questions were the following: (1) "It is important for everybody to have routine vaccinations", (2) "Vaccines are only important for children"; (3) "Not getting vaccinated can lead to serious health issues"; (4) "Vaccines are important to protect not only yourself but also others", (5) "Vaccination of other people is important to protect those that cannot be vaccinated (e.g. newborn children, immunodepressed or very sick people)". The responses to the attitudes questions has been recoded on a scale 1 = "totally agree", 2 = "tend to agree", 3 = "tend to disagree", 4 = "totally disagree", $5=$ "don't know". We reverse scored all responses, except from the item (2), recoded response "don't know" as a middle of the scale, and averaged them $(M=3.11, S E=0.80)$; so that higher scores mean more positive attitudes toward the vaccination.

\section{Plan of analysis}

We analysed the relationships between ideology and vaccine beliefs and attitudes across European countries. We assessed the effects of political ideology and their interaction with education and with political interests on vaccination beliefs and attitudes. In every model, we controlled for participants' demographic characteristics (age, gender, and education). We ran multilevel regressions in which participants were nested within countries (we estimated random intercept as well as random slopes of political ideology and education or ideology and political interest, depending what the focal predictors were $\left.{ }^{1}\right)$. We used Maximum Likelihood to estimate all the models. The slopes for the interactions were probed at $+/-1$ SD. The predictors has been scaled between $0-1$ and additionally the continuous ones have been centered.

\footnotetext{
${ }^{1}$ This is because models with more than 2 random slopes did not converge. Thus, we ran separate models with the interaction between political ideology and education and separate model with the interaction between political ideology and political interest.
} 
Furthermore, as already mentioned, we ran separate analysis for Poland. For that reason we repeat all the analysis but instead of multilevel regression, we ran linear regression.

We used R (R Core Team, 2019) and RStudio (RStudio Team, 2019) with the haven (Wickham \& Miller, 2019), tidyverse (Wickham, 2019), scales (Wickham, 2020), Imer (Bates et al., 2015), ImerTest (Kuznetsova et al., 2017), optimx (Nash, 2014; Nash \& Varadhan, 2011) emmeans (Lenth, 2019), effects (Fox \& Weisberg, 2018), multcomp (Hothorn et al., 2008), ggeffects (Lüdecke, 2018a), sjPlot (Lüdecke, 2018b) packages to clean, analyse, and present the data.

\section{Results}

\section{Analysis for European countries}

We have found that the political ideology is unrelated to vaccine beliefs and attitudes: in the models which included interaction with education, we have found only strong main effects of education but not of political ideology. The model details are presented in Table 1. However, when we focused on political interest instead of education, we found that it interacted with political ideology. Specifically, for the vaccine beliefs, for people interested in politics, right-wing ideology had negative effects $(b=-0.03, S E=0.01, \mathrm{Cl}[-0.06,-0.01])$, whereas for people how are not interested in politics, the effects of ideology were insignificant $(b=0.015, \mathrm{SE}=0.01, \mathrm{CI}[-0.01,0.04])$, the two slopes differed significantly from each other $(b=0.05, \mathrm{SE}=0.02, z=2.52, p=.012)$.

Similar effects were found for the vaccine attitudes: for people interested in politics, right-wing ideology had negative effects $(b=-0.02, S E=0.01, C I[-0.03,-0.001])$, whereas for people who are not interested in politics, the effects of ideology were insignificant $(b=0.01, \mathrm{SE}=0.01, \mathrm{Cl}[-0.01,0.03])$, the two slopes differed significantly from each other $(b=0.03, \mathrm{SE}=0.01, z=2.85, p=.004)$. The model details are presented in Table 1 and the interactive effects of ideology and political interest are shown in Figure 1. 

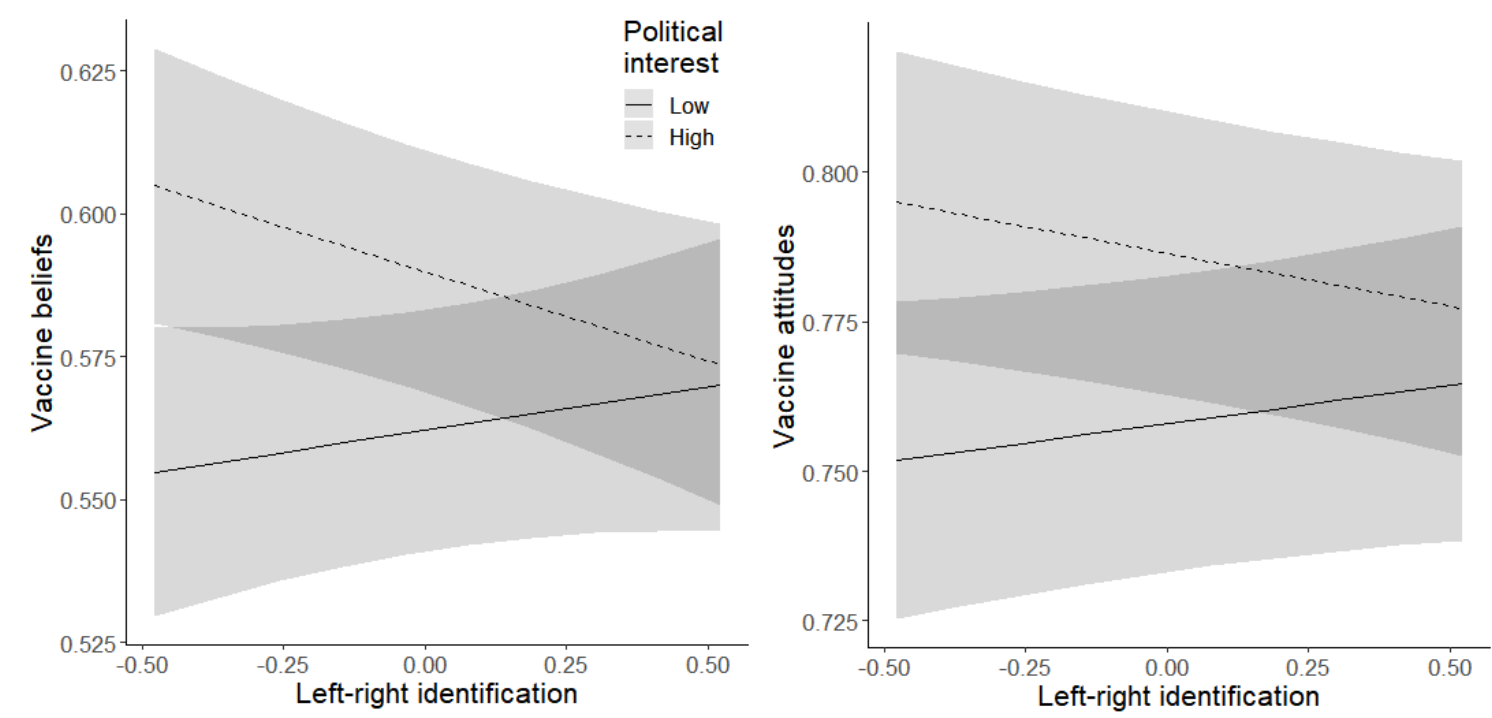

Figure 1. The interactive effects of ideology and political interest on vaccine beliefs and attitudes (data from all countries).

Table 1

The effects of ideology, education, and political interest on vaccine beliefs and attitudes (data from all countries)

\begin{tabular}{|c|c|c|c|c|c|c|c|c|c|c|c|c|}
\hline & \multicolumn{3}{|c|}{ Beliefs } & \multicolumn{3}{|c|}{ Beliefs } & \multicolumn{3}{|c|}{ Attitudes } & \multicolumn{3}{|c|}{ Attitudes } \\
\hline & $b$ & $S E$ & $p$ & $b$ & $S E$ & $p$ & $b$ & $S E$ & $p$ & $b$ & $S E$ & $p$ \\
\hline Intercept & 0.48 & 0.01 & $<0.001$ & 0.57 & 0.01 & $<0.001$ & 0.77 & 0.01 & $<0.001$ & 0.77 & 0.01 & $<0.001$ \\
\hline Gender & -0.00 & 0.00 & 0.267 & -0.00 & 0.00 & 0.416 & 0.02 & 0.00 & $<0.001$ & 0.02 & 0.00 & $<0.001$ \\
\hline Age & 0.02 & 0.01 & 0.001 & 0.04 & 0.01 & $<0.001$ & -0.01 & 0.01 & 0.081 & -0.00 & 0.01 & 0.578 \\
\hline Left-right ident. & -0.01 & 0.01 & 0.250 & -0.01 & 0.01 & 0.408 & -0.01 & 0.01 & 0.460 & -0.00 & 0.01 & 0.723 \\
\hline Education & 0.26 & 0.04 & $<0.001$ & 0.40 & 0.04 & $<0.001$ & 0.31 & 0.04 & $<0.001$ & 0.23 & 0.02 & $<0.001$ \\
\hline $\begin{array}{l}\text { Education } \times \text { Left- } \\
\text { right ident. }\end{array}$ & -0.06 & 0.09 & 0.502 & & & & 0.00 & 0.08 & 0.957 & & & \\
\hline Political interest & & & & 0.04 & 0.01 & $<0.001$ & & & & 0.04 & 0.01 & $<0.001$ \\
\hline $\begin{array}{l}\text { Political interest } \mathrm{x} \\
\text { Left-right ident. }\end{array}$ & & & & -0.07 & 0.03 & 0.012 & & & & -0.05 & 0.02 & 0.004 \\
\hline \multicolumn{13}{|l|}{ Random Effects } \\
\hline$\sigma^{2}$ & 0.04 & & & 0.10 & & & 0.03 & & & 0.03 & & \\
\hline$\tau_{00}$ & 0.00 country & & & 0.00 country & & & $0.00 c$ & & & $0.00 \mathrm{co}$ & & \\
\hline \multirow[t]{2}{*}{$\tau_{11}$} & \multicolumn{2}{|c|}{0.00 country.left-right } & & \multicolumn{2}{|c|}{0.00 country.left-right } & & \multicolumn{2}{|c|}{0.00 country.left-right } & & \multicolumn{2}{|c|}{0.00 country.left-right } & \\
\hline & 0.02 country_educa & & & 0.00 country & polit.interest & & $0.03 c$ & itry_education & & $0.00 \mathrm{co}$ & olit.interest & \\
\hline
\end{tabular}




\begin{tabular}{lllll}
$\rho_{01}$ & -0.13 & -0.03 & -0.17 & -0.08 \\
& 0.04 & 0.04 & -0.62 & 28 country \\
\hline $\mathrm{N}$ & 28 country & 28 country & 212 & 21699 \\
\hline Observations & 21699 & 21699 & $0.011 / 0.119$ \\
Marginal $\mathrm{R}^{2} /$ & $0.009 / 0.035$ & $0.011 / 0.038$ & $0.014 / 0.122$ \\
\hline
\end{tabular}

\section{Analysis for Poland}

In the analysis, we found that the effects of political ideology on vaccine beliefs and attitudes were not significant, neither were the interactions between ideology and education or ideology and political interest. The summary of the models is presented below in Table 2 .

Table 2

The effects of ideology, education, and political interest on vaccine beliefs and attitudes (data from Poland only)

\begin{tabular}{|c|c|c|c|c|c|c|c|c|c|c|c|c|}
\hline & \multicolumn{3}{|c|}{ Beliefs } & \multicolumn{3}{|c|}{ Beliefs } & \multicolumn{3}{|c|}{ Attitudes } & \multicolumn{3}{|c|}{ Attitudes } \\
\hline & $b$ & $S E$ & $p$ & $b$ & $S E$ & $p$ & $b$ & $S E$ & $p$ & $b$ & $S E$ & $p$ \\
\hline Intercept & 0.52 & 0.01 & $<0.001$ & 0.52 & 0.01 & $<0.001$ & 2.98 & 0.04 & $<0.001$ & 2.95 & 0.04 & $<0.001$ \\
\hline Gender & -0.00 & 0.02 & 0.994 & -0.00 & 0.02 & 0.982 & 0.07 & 0.05 & 0.186 & 0.09 & 0.05 & 0.061 \\
\hline Age & 0.04 & 0.04 & 0.291 & 0.05 & 0.04 & 0.259 & -0.02 & 0.13 & 0.897 & 0.06 & 0.13 & 0.643 \\
\hline Education & -0.03 & 0.17 & 0.878 & 0.05 & 0.16 & 0.776 & 1.99 & 0.55 & $<0.001$ & 1.55 & 0.53 & 0.003 \\
\hline Left-right ident. & -0.04 & 0.03 & 0.128 & -0.04 & 0.03 & 0.154 & -0.07 & 0.09 & 0.445 & -0.03 & 0.09 & 0.764 \\
\hline $\begin{array}{l}\text { Education x Left- } \\
\text { right ident. }\end{array}$ & 0.60 & 0.56 & 0.285 & & & & 0.76 & 1.87 & 0.684 & & & \\
\hline Political interest & & & & -0.01 & 0.03 & 0.725 & & & & 0.42 & 0.09 & $<0.001$ \\
\hline $\begin{array}{l}\text { Political interest x } \\
\text { Left-right ident. }\end{array}$ & & & & 0.03 & 0.09 & 0.734 & & & & -0.50 & 0.29 & 0.080 \\
\hline Observations & \multicolumn{3}{|l|}{738} & \multicolumn{3}{|l|}{738} & \multicolumn{3}{|l|}{738} & \multicolumn{3}{|l|}{738} \\
\hline$R^{2} / R^{2}$ adjusted & \multicolumn{3}{|c|}{$0.007 / 0.000$} & \multicolumn{3}{|c|}{$0.006 /-0.002$} & \multicolumn{3}{|c|}{$0.026 / 0.020$} & \multicolumn{3}{|c|}{$0.055 / 0.047$} \\
\hline
\end{tabular}

\section{Summary}

The current findings show that the effects of ideology on vaccine are insignificant when European context is considered. Even if there is an interactive impact of ideology and political interest, the effects are rather modest. Furthermore, our findings do not provide support for the hypothesis 
on "liberal bias" against vaccination. We suggest that it lack of the effects of ideology on vaccines in European context is related to the fact that vaccines have not become a strongly politicized issue as in the US.

\section{References}

Baumgaertner B., Carlisle, J.E., Justwan, F. (2018). The influence of political ideology and trust on willingness to vaccinate. PLoS ONE 13, e0191728. https://doi.org/10.1371/journal.pone.0191728

Bates, D., Mächler, M., Bolker, B., \& Walker, S. (2015). Fitting Linear Mixed-Effects Models Using Ime4. Journal of Statistical Software, 67(1). https://doi.org/10.18637/jss.v067.i01

European Commission. (2019). Eurobarometer 91.2: Europeans in 2019, The General Data Protection Regulation, Awareness of the Charter of Fundamental Rights of the European Union, and Europeans' attitudes towards vaccination. https://zacat.gesis.org/webview/velocity?v=2\&mode=documentation\&submode=abstract\&s tudy=http\%3A\%2F\%2F193.175.238.79\%3A80\%2Fobj\%2FfStudy\%2FZA7562

Fox, J., \& Weisberg, S. (2018). Visualizing Fit and Lack of Fit in Complex Regression Models with Predictor Effect Plots and Partial Residuals. Journal of Statistical Software, 87(9). https://doi.org/10.18637/jss.v087.i09

Hornsey, M., Harris, J., \& Fielding,K. (2018).The psychological roots of anti-vaccination attitudes: A 24-nation investigation. Health Psychology, 37, 307-315. http://dx.doi.org/10.1037/hea0000586

Hothorn, T., Bretz, F., \& Westfall, P. (2008). Simultaneous Inference in General Parametric Models. Biometrical Journal, 50(3), 346-363. https://doi.org/10.1002/bimj.200810425

Kahan, D. (2017). Misconceptions, Misinformation, and the Logic of Identity-Protective Cognition. Cultural Cognition Project Working Paper Series No. 164. 
Kuznetsova, A., Brockhoff, P. B., \& Christensen, R. H. B. (2017). ImerTest Package: Tests in Linear Mixed Effects Models. Journal of Statistical Software, 82(13). https://doi.org/10.18637/jss.v082.i13

Lenth, R. (2019). emmeans: Estimated Marginal Means, aka Least-Squares Means. (1.3.2.) [Computer software]. https://CRAN.R-project.org/package=emmeans

Lewandowsky, S., Gignac, G.E., \& Oberauer, K. (2015) Correction: The Role of Conspiracist Ideation and Worldviews in Predicting Rejection of Science. PLOS ONE, 10: e0134773. https://doi.org/10.1371/journal.pone.0134773 V

Lüdecke, D. (2018a). ggeffects: Tidy Data Frames of Marginal Effects from Regression Models. Journal of Open Source Software, 3(26), 772. https://doi.org/10.21105/joss.00772

Lüdecke, D. (2018b). sjPlot-Data Visualization for Statistics in Social Science. (2.8.2) [Computer software]. https://doi.org/10.5281/ZENODO.1308157

Mullard, A. (2020). COVID-19 vaccine development pipeline gears up. The Lancet, 395(10239), 17511752. https://doi.org/10.1016/S0140-6736(20)31252-6

Nash, J. C. (2014). On Best Practice Optimization Methods in R. Journal of Statistical Software, 60(2), 1-14. https://doi.org/10.18637/jss.v060.i02

Nash, J. C., \& Varadhan, R. (2011). Unifying Optimization Algorithms to Aid Software System Users: Optimx for R. Journal of Statistical Software, 43(9). https://doi.org/10.18637/jss.v043.i09

R Core Team. (2019). R: A language and environment for statistical computing. Foundation for Statistical Computing. https://www.R-project.org/

Rutjens, B. T., Heine, S. J., Sutton, R. M., \& van Harreveld, F. (2018). Attitudes Towards Science. In E. S. P. Olson (Ed.), Advances in Experimental Psychology (Vol. 57, pp. 125-165). Academic Press. https://doi.org/https://doi.org/10.1016/bs.aesp.2017.08.001

RStudio Team. (2019). RStudio: Integrated Development for R. RStudio, Inc. http://www.rstudio.com/ Wellcome Trust. (2018). Wellcome Global Monitor.

https://wellcome.ac.uk/sites/default/files/wellcome-global-monitor-2018.pdf 
Wickham, H. (2019). tidyverse: Easily Install and Load the 'Tidyverse'. (1.2.1.) [Computer software]. https://CRAN.R-project.org/package=tidyverse

Wickham, H. (2020). Scales: Scale Functions for Visualization. $R$ package version 1.0.0. https://CRAN.R-project.org/package=scales

Wickham, H., \& Miller, E. (2019). Haven: Import and Export 'SPSS', 'Stata' and 'SAS' Files. R package version 2.1.1. https://CRAN.R-project.org/package=haven 